\title{
Assessment of the Quality and Evaluation of the Antioxidant Potential of a Novel Sri Lankan Ayurvedic Polyherbal Formulation
}

\author{
H. P. Wakkumbura $\left(D,{ }^{1}\right.$ W. M. D. Wickramaarachchi, ${ }^{2}$ L. D. A. M. Arawwawala $\left(\mathbb{D},{ }^{3}\right.$ \\ J. A. Liyanage, ${ }^{4}$ and R. P. V. J. Rajapakse ${ }^{2}{ }^{2}$ \\ ${ }^{1}$ Department of Kaumarabruthya and Stree Roga, Gampaha Wickramarachchi Ayurveda Institute, University of Kelaniya, \\ Yakkala, Sri Lanka \\ ${ }^{2}$ Department of Veterinary Pathobiology, Faculty of Veterinary Medicine and Animal Science, University of Peradeniya, \\ Sri Lanka \\ ${ }^{3}$ Industrial Technology Institute, Bauddhaloka Mawatha, Colombo 07, Sri Lanka \\ ${ }^{4}$ Department of Chemistry, Faculty of Science, University of Kelaniya, Yakkala, Sri Lanka
}

Correspondence should be addressed to H. P. Wakkumbura; hemaw@kln.ac.lk

Received 23 March 2020; Revised 17 June 2020; Accepted 24 June 2020; Published 18 July 2020

Guest Editor: Yuan Xu

Copyright (c) 2020 H. P. Wakkumbura et al. This is an open access article distributed under the Creative Commons Attribution License, which permits unrestricted use, distribution, and reproduction in any medium, provided the original work is properly cited.

\begin{abstract}
Background. In Sri Lanka, a Polyherbal Ayurvedic Formulation (PHAF), which consists of powders of seven medicinal plants, is being trialed for use as an anti-inflammatory drug. In general, anti-inflammatory drugs have good antioxidant properties. Therefore, in the present study, an attempt was made to assess the quality and evaluate the antioxidant potential of PHAF. Methods. Physicochemical parameters such as ash content, extractable matter, phytochemical screening for secondary metabolites, levels of heavy metals, and microbes were determined according to standard protocols. Antioxidant activity was evaluated using five in vitro assays: total polyphenolic content (TPC), total flavonoid content (TFC), ORAC (oxygen radical absorbance capacity), DPPH (1,1-diphenyl-2-picryl-hydrazyl), and ABTS (2,2-azino-bis(3-ethylbenzothiazoline-6-sulfonic acid) diammonium salt. Results. PHAF contained $5.6 \pm 0.2 \%$ of moisture, $6.5 \pm 0.1 \%$ of total ash, $1.4 \pm 0.1 \%$ of water soluble ash, $0.9 \pm 0.0 \%$ of acid insoluble ash, $7.7 \pm 0.2 \%$ of hot water extractable matter, $3.9 \pm 0.1 \%$ of cold water extractable matter, $10.5 \pm 4.1 \%$ of hot-ethanol extractable matter, and $8.4 \pm 0.2 \%$ of cold-ethanol extractable matter. Phytochemical screening revealed the presence of phenolic compounds, tannins, flavonoids, coumarins, and saponins in both aqueous and ethanolic extracts of the drug. TPC, TFC, ORAC, DPPH, and ABTS of aqueous and ethanol extracts of PHAF were $103.65 \pm 4.94$ and $327.07 \pm 9.65 \mathrm{mg}$ gallic acid equivalents/g extract, $76.6 \pm 5.83$ and $224.6 \pm 8.42 \mathrm{mg}$ quercetin equivalents/g of extract, $481.11 \pm 17.30$ and $1481.44 \pm 30.20 \mathrm{mg}$ trolox equivalents/g of extract, $79.50 \pm 4.42$ and $227.17 \pm 6.16 \mathrm{mg}$ trolox equivalents/g of extract, and $198.20 \pm 4.55$ and $577.08 \pm 5.48 \mathrm{mg}$ trolox equivalents/g of extract, respectively. Conclusion. Ethanolic extract of PHAF is better than aqueous extract in terms of antioxidant properties.
\end{abstract}

\section{Introduction}

Since prehistoric times, herbs were the basis for nearly all medicinal therapy until synthetic drugs were developed in the nineteenth century, a time when the prominence of herbal remedies gradually decreased in developed countries $[1,2]$. Interest in herbal medicine has increased recently, with their efficacy again being researched and identified. Plant-based compounds and formulations for treatment of various ailments are becoming common place in society. Moreover, $75-80 \%$ of the world's population in developing countries continues to use herbal medicines for primary healthcare. However, quality assessments of herbal medicines are frequently lacking, something urgently required for the safety of users.

Free radicals are molecular species or atoms which contain one or more unpaired electrons. These are constantly produced in the human body as a result of cell metabolism [3]. Free radicals have important roles in gene 
expression and activation of receptors as well as in regulation of signal transduction [4]. However, an excess of free radicals can become toxic to living cells [5] and may cause many diseases such as cancer, atherosclerosis, neurodegenerative diseases, and inflammation [6-8].

Previous researches have indicated that phenolic compounds and flavonoids act as excellent anti-inflammatory agents [9]. Due to the relation of these compounds towards antioxidant activity, it is important to evaluate the antioxidant potential.

A novel Polyherbal Ayurvedic Formulation (PHAF), which consists of powders of seven medicinal plants ( $\mathrm{Ta}-$ ble 1), is being trialed for use as an anti-inflammatory drug in Sri Lanka. As PHAF has shown promising anti-inflammatory activity in initial studies, in the present study, an attempt was done to assess the quality and evaluate the antioxidant potential of the drug.

\section{Materials and Methods}

2.1. Plant Ingredients. Fresh plant materials required for $\mathrm{PHAF}$ were collected from Colombo $\left(6^{\circ} 55^{\prime} 54.98^{\prime \prime} \mathrm{N} \times 79^{\circ} 50^{\prime}\right.$ $52.01^{\prime \prime}$ E) Western province, Sri Lanka, and authenticated by the Curator of National Herbarium of Peradeniya, Sri Lanka. The plant materials were identified and authenticated by Prof. M. H. A. Tissera, Professor in Dravyaguna, Department of Dravyaguna, Gampaha Wickramarachchi Ayurveda Institute, University of Kelaniya, Yakkala, Sri Lanka. A voucher specimen from each plant (PHAF1-7) was deposited at Department of Kaumarabruthya and Stree Roga, Gampaha Wickramarachchi Ayurveda Institute, University of Kelaniya, Yakkala, Sri Lanka, for future reference.

2.2. Preparation of Polyherbal Ayurvedic Formulation $(P H A F)$. In brief, all the ingredients were washed thoroughly and air dried. Then ingredients were pulverized separately into a coarse powder and combined in a stainless steel vessel in a ratio of $1: 1(\mathrm{w} / \mathrm{w})$ and mixed well.

\subsection{Preparation of Hot-Ethanol Extract from Polyherbal} Ayurvedic Formulation (PHAF). PHAF powder (50 g) was added to a round bottom flask containing $150 \mathrm{~mL}$ of ethanol and boiled for $4 \mathrm{~h}$. Then, the extract was filtered using Whatman $0.45 \mu \mathrm{m}$ filter paper, and the filtrate was concentrated using a rotary evaporator (yield: $9.2 \% \mathrm{w} / \mathrm{w}$ ) and stored at $4^{\circ} \mathrm{C}$ until used.

2.4. Preparation of Hot-Water Extract from Polyherbal Ayurvedic Formulation (PHAF). PHAF powder (50 g) was added to a round bottom flask containing $150 \mathrm{~mL}$ of water and boiled for $4 \mathrm{~h}$. Then, the extract was filtered using Whatman $0.45 \mu \mathrm{m}$ filter paper and the filtrate was concentrated using a rotary evaporator and freeze dried (yield: $12.5 \% \mathrm{w} / \mathrm{w}$ ) and stored at $4^{\circ} \mathrm{C}$ until used.

2.5. Physicochemical Investigation. Physicochemical parameters of PHAF powder were assayed according to the World Health Organization (WHO) guidelines on quality control methods for herbal materials [10]. Physicochemical parameters such as water extractable matter (both hot and cold), ethanol extractable matter (both hot and cold), total ash, water soluble ash, acid insoluble ash, and moisture content were investigated.

2.6. Qualitative Phytochemical Screening. Phytochemical screening was carried out for PHAF (ethanol and aqueous extracts) according to methods described by Yadav and Agarwala [11] with slight modifications.

2.7. Determination of Heavy Metal Content. Quantitative determination of arsenic (As) [12], mercury (Hg) [13], cadmium (Cd) [13], and lead $(\mathrm{Pb})$ [12] was carried out according to the Association of Official Agricultural Chemists (AOAC) methods using an Inductively Coupled Plasma Mass Spectrometry.

2.8. Determination of Microbial Limits. Microbial tests for aerobic plate count [14], coliform count [15], yeasts and moulds count [16], Escherichia coli [17], Salmonella [18], and Staphylococcus aureus [19] were carried out as per standard procedures detailed in Sri Lanka Standards.

2.9. Evaluation of Antioxidant Activity. Antioxidant activity of the ethanol and aqueous extracts of PHAF powder was investigated using the following in vitro assays.

2.9.1. Total Polyphenolic Content (TPC). Total polyphenol content of ethanol and aqueous extracts of PHAF was determined using the Folin-Ciocalteu reagent [20] in 96-well microplates with some modifications. Absorbance was recorded at $765 \mathrm{~nm}$ and gallic acid was used to construct the standard curve. TPC of ethanol and aqueous extracts of PHAF were expressed as mg gallic acid equivalents per gram of extract on a dry weight basis.

2.9.2. Total Flavonoid Content (TFC). Total flavonoid content of ethanol and aqueous extracts of PHAF was determined using the aluminium chloride method in 96-well microplates [21] with some modifications. Absorbance was recorded at $415 \mathrm{~nm}$ and quercetin was used to construct the standard curve. TFCs of ethanol and aqueous extracts of PHAF were expressed as mg quercetin equivalents per gram of extract on a dry weight basis.

2.9.3. DPPH Radical Scavenging Activity. The DPPH (1,1diphenyl-2-picrylhydrazyl) radical scavenging assay was performed in 96-well microplates according to the method described by Blois [22] with some modifications. Absorbance was recorded at $517 \mathrm{~nm}$ and trolox $(12.5,6.25,3.12$, 1.56 , and $0.78 \mu \mathrm{g} / \mathrm{mL}$ ) was used to construct the standard curve. Results were expressed as trolox equivalents antioxidant capacity ( $\mathrm{mg}$ trolox equivalents per gram of extract) on a dry weight basis. 
Table 1: Composition of Polyherbal Ayurvedic Formulation (PHAF).

\begin{tabular}{lccc}
\hline No. & Scientific name & Family & Amount and part of the plant used \\
\hline 1 & Cassia fistula Linn. & Fabaceae & Bark (10 g) \\
2 & Glycyrrhiza glabra Linn. & Seguminosae & Stem (10 g) \\
3 & Coscinium fenestratum (Goetgh.) Colebr. & Menispermaceae & Stem (10 g) \\
4 & Cyperus rotundus Linn. & Cyperaceae & Rhizome $(10 \mathrm{~g})$ \\
5 & Curcuma longa Linn. & Zingiberaceae & Rhizome $(10 \mathrm{~g})$ \\
6 & Azadirachta indica A. Juss. & Meliaceae & Bark (10 g) \\
7 & Stereospermum suaveolens (Roxb.) DC. & Bignoniaceae & Bark (10 g) \\
\hline
\end{tabular}

2.9.4. $\mathrm{ABTS}^{+}$Radical Scavenging Activity. The $\mathrm{ABTS}^{+}(2,2-$ azino-bis(3-ethylbenzthiazoline-6-sulfonic acid) radical scavenging assay was performed in 96-well microplates according to the method described by Re [23] with some modifications. Trolox was used to construct the standard curve, and results were expressed as trolox equivalents antioxidant capacity (mg trolox equivalents per gram of extract) on a dry weight basis.

2.9.5. Oxygen Radical Absorbance Capacity (ORAC). The ORAC radical scavenging assay was performed in 96-well microplates according to the method described by $\mathrm{Ou}$ [24] with some modification. The assay was conducted at $37^{\circ} \mathrm{C}$ and $\mathrm{pH} 7.4$, with a blank sample in parallel. Trolox standards (1.5 and $0.75 \mu \mathrm{g} / \mathrm{mL})$, fluorescein $(4.8 \mu \mathrm{M})$, and 2,2-azobis(2amidinopropane) dihydrochloride (AAPH) $(40 \mathrm{mg} / \mathrm{mL})$ solutions were prepared in phosphate buffer $(75 \mathrm{mM}, \mathrm{pH}$ 7.4) prior to use. Ethanol or aqueous extracts of PHAF were initially dissolved in DMSO. Reaction volumes of $200 \mu \mathrm{L}$ containing $100 \mu \mathrm{L}$ of $4.8 \mathrm{Mm}$ fluorescein and $50 \mu \mathrm{L}$ of 15.62 and $7.81 \mu \mathrm{g} / \mathrm{mL}$ of different concentrations of ethanol and aqueous extracts of PHAF were preincubated at $37^{\circ} \mathrm{C}$ for 10 minutes followed by addition of $50 \mu \mathrm{L}$ of AAPH $(40 \mathrm{mg} / \mathrm{mL})$ to each well to initiate the reaction. The plate was placed on the fluorescent microplate reader (SpectraMax-Gemini EM, Molecular Devices Inc., USA) set with excitation and emission at $494 \mathrm{~nm}$ and $535 \mathrm{~nm}$ and decay of fluorescein was recorded in 1-minute intervals for 60 minutes. Results were expressed as trolox equivalents antioxidant capacity (mg trolox equivalents per gram of extract) on a dry weight basis.

2.10. Statistical Analysis. Data were statistically analyzed using GraphPad Prism version 4.0. One-way analysis of variance (ANOVA) and Duncan's multiple range test were used to determine the differences among treatment means. $P<0.05$ was regarded as significant.

\section{Results}

3.1. Physicochemical Parameters. Physicochemical parameters of PHAF are illustrated in Table 2.

3.2. Phytochemical Screening. Tannins, flavonoids, saponins, coumarins, and phenolic compounds were present in both hot water and hot-ethanol extracts. Alkaloids and cardiac glycosides were present only in aqueous extract.
Table 2: Physicochemical parameters of Polyherbal Ayurvedic Formulation (PHAF).

\begin{tabular}{lc}
\hline Physicochemical parameters & Amount (\% dry weight basis) \\
\hline Moisture content & $5.6 \pm 0.2$ \\
Total ash content & $6.5 \pm 0.1$ \\
Water soluble ash content & $1.4 \pm 0.1$ \\
Acid insoluble ash content & $0.9 \pm 0.0$ \\
Hot-ethanol extractable matter & $10.5 \pm 4.1$ \\
Cold-ethanol extractable matter & $8.4 \pm 0.2$ \\
Hot-water extractable matter & $7.7 \pm 0.2$ \\
Cold-water extractable matter & $3.9 \pm 0.1$ \\
\hline
\end{tabular}

Data represented as mean \pm SEM (standard error mean); $n=6$.

3.3. Heavy Metals. Heavy metals such as $\mathrm{Pb}, \mathrm{Cd}, \mathrm{Hg}$, and $\mathrm{As}$ were not detected in PHAF. The minimum detection levels of $\mathrm{Pb}, \mathrm{Cd}, \mathrm{Hg}$, and As were $0.5 \mathrm{ppm}, 0.05 \mathrm{ppm}, 0.05 \mathrm{ppm}$, and $0.05 \mathrm{ppm}$, respectively.

3.4. Microbial Limits. Microbes including Escherichia coli, Coliforms, and Salmonella were not present in the PHAF. Aerobic plate counts revealed few $(<10 \mathrm{CFU} / \mathrm{g})$ yeasts and moulds $(<10 \mathrm{CFU} / \mathrm{g})$ and Staphylococcus aureus $(<10 / \mathrm{g})$.

3.5. Antioxidant Properties. Antioxidant properties of ethanol and aqueous extracts of PHAF powder are given in Table 3.

\section{Discussion}

In the present study, significantly more matter was extracted by ethanol than by water. Further, more extractable matter was present in hot extracts than in cold extracts (both water and ethanol). Very little acid insoluble ash was present in PHAF (Table 2), indicating the absence of silica-like impurities in the drug.

The main purpose of our study was to evaluate antioxidant activity of PHAF by using in vitro assays. Antioxidant activity has been evaluated previously for each of the seven plant species present in PHAF. Examples include antioxidant activities for C. rotundus [25, 26], C. longa [27], A. indica [28], C. fistula [29, 30], C. fenestratum [31], and S. suaveolens [32]. G. glabra, one of the ingredients in PHAF, is rich in glycyrrhizic acid which exhibits significant antioxidant activity [33].

According to traditional Ayurveda practice, PHAF is administered to patients in the hot water extract form. We, therefore, assayed antioxidant activities for the aqueous 
Table 3: Antioxidant properties of Polyherbal Ayurvedic Formulation (PHAF).

\begin{tabular}{|c|c|c|c|c|c|}
\hline \multirow[b]{2}{*}{ Samples } & \multicolumn{5}{|c|}{ Antioxidant properties } \\
\hline & $\begin{array}{c}\text { TPC } \\
\text { (mg gallic acid } \\
\text { equivalents/g of extract) }\end{array}$ & $\begin{array}{c}\text { TFC } \\
\text { (mg quercetin } \\
\text { equivalents/g of extract) }\end{array}$ & $\begin{array}{c}\text { ORAC } \\
\text { (mg trolox } \\
\text { equivalents/g of } \\
\text { extract) }\end{array}$ & $\begin{array}{c}\mathrm{DPPH} \\
\text { (mg trolox equivalents/ } \\
\mathrm{g} \text { of extract) }\end{array}$ & $\begin{array}{c}\text { ABTS } \\
\text { (mg trolox equivalents/ } \\
\text { g of extract) }\end{array}$ \\
\hline $\begin{array}{l}\text { Ethanol } \\
\text { extract }\end{array}$ & $327.07 \pm 9.65^{*}$ & $224.6 \pm 8.42^{*}$ & $1481.44 \pm 30.20^{*}$ & $227.17 \pm 6.16^{*}$ & $577.08 \pm 5.48^{*}$ \\
\hline $\begin{array}{l}\text { Aqueous } \\
\text { extract }\end{array}$ & $103.65 \pm 4.94$ & $76.6 \pm 5.83$ & $481.11 \pm 17.30$ & $79.50 \pm 4.42$ & $198.20 \pm 4.55$ \\
\hline
\end{tabular}

Data represented as mean \pm SEM (standard error mean). ${ }^{*}$ Significant when compared to the respective values of TPC, TFC, ORAC, DPPH, and ABTS of aqueous extract; $P<0.05$. TPC: total polyphenol content $(n=6)$; TFC: total flavonoid content $(n=6)$; ORAC: oxygen radical absorbance capacity $(n=5)$; DPPH: 1,1-diphenyl-2-picryl-hydrazyl; ABTS: 2,2-azino-bis(3-ethylbonzothiazoline-6-sulfonic acid) diammonium salt ( $n=4$ each).

extract. However, hot water preparations have some drawbacks, such as unpleasant taste, and have lower stability, requiring them to be prepared freshly on each occasion. To avoid this drawback, it would be better to develop pharmaceutics such as syrups and tonics. Therefore, we also assayed the ethanol extract of PHAF, which exhibited overall higher levels of antioxidant activities than that of aqueous extract (Table 3). Ethanol extract is safe compared to other solvent (e.g., hexane, methanol, and acetone) extracts, and one of the targets of the present study is to formulate a modern drug from PHAF. Therefore, antioxidant potential of PHAF was compared with only water and ethanol extracts.

In $\mathrm{ABTS}^{+}$assay, a blue/green $\mathrm{ABTS}^{+}$chromophore is generated by the oxidation of ABTS with potassium persulfate. Antioxidants which have the ability of donating hydrogen reduced the blue/green color of $\mathrm{ABTS}^{+}$and can be measured spectrophotometrically at $745 \mathrm{~nm}$ [34]. $\mathrm{DPPH}$ is a stable synthetic radical and does not deteriorate in water, methanol, or ethanol [35]. In DPPH assay, presence of hydrophilic antioxidants such as proton radical scavengers or hydrogen donors, reduced the color of DPPH to straw color $[36,37]$ from its original deep violet color at $517 \mathrm{~nm}$. Moreover, the DPPH assay determines only the hydrophilic antioxidants whereas the ABTS $^{+}$assay measures both hydrophilic and lipophilic antioxidants [23].

In the present study, $\mathrm{IC}_{50}$ values of $\mathrm{ABTS}^{+}$(for both aqueous and ethanol extracts) were significantly lower than that of DPPH (Figure 1). This indicates that, in addition to hydrophilic antioxidants, lipophilic antioxidants play a major role in scavenging free radicals. Similar activity is exhibited in many plants such as Toddalia asiatica, Glinus oppositifolius, Spondias pinnata, and Aganonerion polymorphum [38]. In contrast, some plant extracts such as Sonchus asper [39] have shown more radical scavenging properties in the $\mathrm{DPPH}^{\cdot}$ assay than in the $\mathrm{ABTS}^{+}$assay.

The capacity of a compound to scavenge peroxyl radicals, generated by spontaneous decomposition of 2,2'-azobis(2amidinopropane) dihydrochloride (AAPH), was estimated in the ORAC assay. The ORAC value is directly proportional to the degree of antioxidant power $[36,40]$.
Phenolic compounds and flavonoids are reported to have antioxidant and free-radical scavenging activity $[41,42]$. They perform scavenging activity by stabilizing free radicals via their conjugated ring structures and hydroxyl groups [43]. The high quantity of phenolic and flavonoid contents of PHAF may contribute to its high antioxidant property. Therefore, ethanol extract of this drug has more radical scavenging activity towards both $\mathrm{ABTS}^{+}$and DPPH than aqueous extract of the drug. Similar results have been shown with Foeniculum vulgare [44]. Among the plant metabolites, polyphenols and flavonoids are promising in governing number of bioactivities as antidiabetic, antioxidant, hepatoprotective, antimicrobial, anti-inflammatory, etc. [45, 46]. Therefore, presence of high content of polyphenols and flavonoids may play a major role in proven antiinflammatory activity of PHAF.

The ash content is a criterion to judge the identity and purity of crude drugs $[47,48]$. A high acid insoluble ash content is indicative of contamination, substitution, adulteration, or carelessness in preparing the samples for marketing. Acid-insoluble ash indicates contamination with silica, for example. earth and sand $[49,50]$. Therefore, the low acid insoluble ash content in PHAF indicates high purity of the drug. Furthermore, very low levels of microbes in PHAF indicate good manufacturing practices during preparation. In addition, heavy metals such as $\mathrm{Hg}, \mathrm{Pb}, \mathrm{As}$, and Cd were not present in PHAF. The extractable matter value is useful for the evaluation of a crude drug as it gives an idea about the nature of chemical constituents present in the drug. In addition, it is useful for the estimation of chemical constituents soluble in a particular solvent used for extraction [50].

The phytochemical constituents of many medicinal plants have been recorded by a number of researchers during the last few decades $[47,50,51]$. The most important bioactive compounds in medicinal plants are alkaloids, flavonoids, and phenolic compounds [52, 53]. The plant extracts in the present study also contained saponins, which are known to produce inhibitory effects on inflammation [54]. Furthermore, antioxidants are known to have potential against different disease conditions such as diabetes, cancer, cardiovascular disease, Alzheimer's 


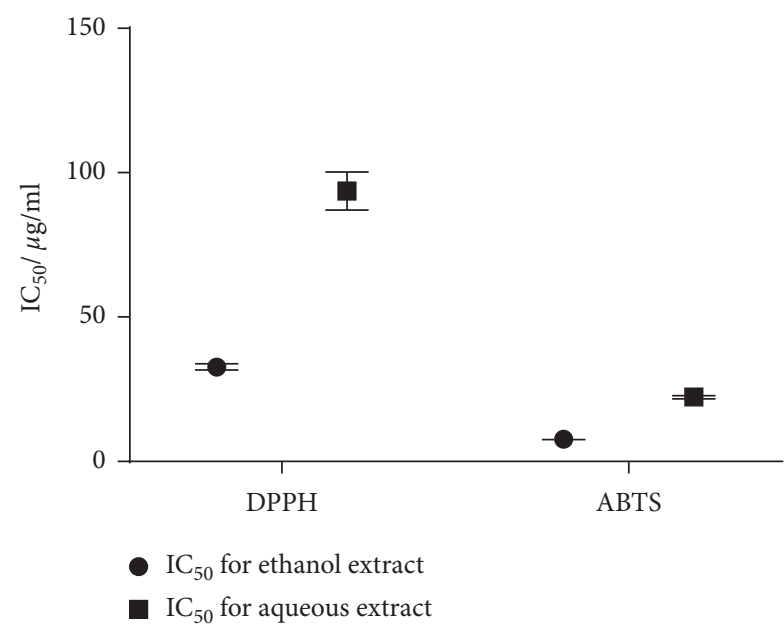

FIGURE 1: $\mathrm{IC}_{50}$ values of aqueous and ethanol extracts of Polyherbal Ayurvedic Formulation (PHAF) for $\mathrm{ABTS}^{+}$and DPPH assays.

disease, Down's syndrome, Parkinson's disease, and schizophrenia [55-59]. As PHAF is rich in antioxidants, this polyherbal formulation will be beneficial to the world.

\section{Conclusions}

We have reported the quality assessment and antioxidant properties of PHAF for the first time. PHAF has potent antioxidant properties, which may be due to the presence of high content of polyphenols and flavonoids. Even though aqueous extract of PHAF is used in traditional practice, ethanol extract can be used to formulate pharmaceuticals such as tonics and syrups due to its potent antioxidant properties.

\section{Data Availability}

All the data obtained and materials analyzed in this research are available from the corresponding author upon request and also can be accessed from Ph.D. thesis of the corresponding author deposited at the University of Kelaniya, Sri Lanka.

\section{Disclosure}

The funding sponsor had no role in the study design, performance, data collection and analysis, decision to publish, or preparation/writing of the manuscript.

\section{Conflicts of Interest}

The authors declare that they have no conflicts of interest.

\section{Acknowledgments}

The authors would like to acknowledge Industrial Technology Institute for providing laboratory facilities for the research. This study was supported by the funding from University Grants Commission, Sri Lanka (UGC/ICD/CRF 2009/2/45).

\section{References}

[1] S. A. Dahanukar, R. A. Kulkarni, and N. N. Rege, "Pharmacology of medicinal plants and natural product," Indian Journal of Pharmacology, vol. 32, no. 4, pp. S81-S118, 2000.

[2] V. Exarchou, N. Nenadis, M. Tsimidou, I. P. Gerothanassis, A. Troganis, and D. Boskou, "Antioxidant activities and phenolic composition of extracts from greek oregano, greek sage, and summer savory," Journal of Agricultural and Food Chemistry, vol. 50, no. 19, pp. 5294-5299, 2002.

[3] B. Halliwell and J. M. C. Gutteridge, Free Radicals in Biology and Medicine, Clarendon Press, Oxford, UK, 4th edition, 2006.

[4] T. A. Ajith and K. K. Janardhanan, "Indian medicinal mushrooms as a source of antioxidant and antitumor agents," Journal of Clinical Biochemistry and Nutrition, vol. 40, no. 3, pp. 157-162, 2007.

[5] H. Liu and G. A. Visner, "Oxidants and antioxidants," Molecular Pathology of Lung Diseases, vol. 1, 2008.

[6] S. Y. Tang, M. Whiteman, Z. F. Peng, A. Jenner, E. L. Yong, and B. Halliwell, "Characterization of antioxidant and antiglycation properties and isolation of active ingredients from traditional Chinese medicines," Free Radical Biology and Medicine, vol. 36, no. 12, pp. 1575-1587, 2004.

[7] Y. Cai, Q. Luo, M. Sun, and H. Corke, "Antioxidant activity and phenolic compounds of 112 traditional Chinese medicinal plants associated with anticancer," Life Sciences, vol. 74, no. 17, pp. 2157-2184, 2004.

[8] T. Hemnani and M. S. Parihar, "Reactive oxygen species and oxidative DNA damage," Indian Journal of Physiology and Pharmacology, vol. 42, no. 4, pp. 440-452, 1998.

[9] R. S. Talhouk, C. Karam, S. Fostok, W. El-Jouni, and E. K. Barbour, "Anti-inflammatory bioactivities in plant extracts," Journal of Medicinal Food, vol. 10, no. 1, pp. 1-10, 2007.

[10] WHO, General Guidelines for Methodologies on Research and Evaluation of Traditional Medicine, World Health Organization, Geneva, Switzerland, 2000.

[11] R. N. S. Yadav and M. Agarwala, "Phytochemical analysis of some medicinal plants," Journal of Phytology, vol. 3, no. 12, pp. 10-14, 2001.

[12] AOAC International, Official Methods Of Analysis Of Aoac International, vol. 975, no. 3, AOAC International, Garthersburg, MA, USA, 2012.

[13] AOAC International, Official Methods of Analysis of AOAC International, AOAC International, Garthersburg, MA, USA, 2012.

[14] Sri Lanka Standards Institution, Sri Lanka standards, Vol. 516/1, Sri Lanka Standards Institution, Colombo, Sri Lanka, 2013.

[15] Sri Lanka Standards Institution, Sri Lanka standards, Vol. 516/2, Sri Lanka Standards Institution, Colombo, Sri Lanka, 1991.

[16] Sri Lanka Standards Institution, Sri Lanka standards, Vol. 516/3, Publication of Sri Lanka Standards Institution, Colombo, Sri Lanka, 2013.

[17] Sri Lanka Standards Institution, Sri Lanka standards, Vol. 516/12, Publication of Sri Lanka Standards Institution, Colombo, Sri Lanka, 2013. 
[18] Sri Lanka Standards Institution, Sri Lanka standards, Vol. 516/5, Publication of Sri Lanka Standards Institution, Colombo, Sri Lanka, 2013.

[19] Sri Lanka Standards Institution, Sri Lanka standards, Vol. 516/6, Publication of Sri Lanka Standards Institution, Colombo, Sri Lanka, 1992.

[20] V. L. Singleton, R. Orthofer, and R. M. Lamuela-Raventós, "Analysis of total phenols and other oxidation substrates and antioxidants by means of folin-ciocalteu reagent," Oxidants and Antioxidants Part A, vol. 299, pp. 152-178, 1999.

[21] A. Meda, C. E. Lamien, M. Romito, J. Millogo, and O. G. Nacoulma, "Determination of the total phenolic, flavonoid and proline contents in burkina fasan honey, as well as their radical scavenging activity," Food Chemistry, vol. 91, no. 3, pp. 571-577, 2005.

[22] M. S. Blois, "Antioxidant determinations by the use of a stable free radical," Nature, vol. 181, no. 4617, pp. 1199-1200, 1958.

[23] R. Re, N. Pellegrini, A. Proteggente, A. Pannala, M. Yang, and C. Rice-Evans, "Antioxidant activity applying an improved ABTS radical cation decolorization assay," Free Radical Biology and Medicine, vol. 26, no. 9-10, pp. 1231-1237, 1999.

[24] B. Ou, M. Hampsch-Woodill, and R. L. Prior, "Development and validation of an improved oxygen radical absorbance capacity assay using fluorescein as the fluorescent probe," Journal of Agricultural and Food Chemistry, vol. 49, no. 10, pp. 4619-4626, 2001.

[25] W.-G. Seo, H.-O. Pae, G.-S. Oh et al., "Inhibitory effects of methanol extract of Cyperus rotundus rhizomes on nitric oxide and superoxide productions by murine macrophage cell line, RAW 264.7 cells," Journal of Ethnopharmacology, vol. 76, no. 1, pp. 59-64, 2001.

[26] S. Kilani, S. M. Ben, I. Limem, I. Bouhlel, J. Boubaker, and W. Bhouri, "In vitro evaluation of antibacterial, antioxidant, cytotoxic and apoptotic activities of the tubers infusion and extracts of Cyperus rotundus," Bioresource Technology, vol. 99, no. 18, pp. 9004-9008, 2008.

[27] A. J. Ruby, G. Kuttan, K. Dinesh Babu, K. N. Rajasekharan, and R. Kuttan, "Anti-tumour and antioxidant activity of natural curcuminoids," Cancer Letters, vol. 94, no. 1, pp. 79-83, 1995.

[28] B. Sultana, F. Anwar, and R. Przybylski, "Antioxidant activity of phenolic components present in barks of Azadirachta indica, Terminalia arjuna, Acacia nilotica, and Eugenia jambolana Lam. trees," Food Chemistry, vol. 104, no. 3, pp. 1106-1114, 2007.

[29] R. Ilavarasan, M. Mallika, and S. Venkataraman, "Anti-inflammatory and antioxidant activities of Cassia fistula Linn bark extracts," African Journal of Traditional, Complementary and Alternative Medicine, vol. 2, no. 1, pp. 70-85, 2005.

[30] P. Siddhuraju, P. S. Mohan, and K. Becker, "Studies on the antioxidant activity of Indian Laburnum (Cassia fistula L.): a preliminary assessment of crude extracts from stem bark, leaves, flowers and fruit pulp," Food Chemistry, vol. 79, no. 1, pp. 61-67, 2002.

[31] I. R. Punitha, K. Rajendran, A. Shirwaikar, and A. Shirwaikar, "Alcoholic stem extract of Coscinium fenestratumRegulates carbohydrate metabolism and improves antioxidant status in streptozotocin-nicotinamide induced diabetic rats," EvidenceBased Complementary and Alternative Medicine, vol. 2, no. 3, pp. 375-381, 2005.

[32] V. M. Chandrashekhar, A. A. Muchandi, S. V. Sudi, and S. Ganapty, "Hepatoprotective activity of Stereospermum suaveolens against $\mathrm{CCl}_{4}$-induced liver damage in albino rats," Pharmaceutical Biology, vol. 48, no. 5, pp. 524-528, 2010.

[33] O. A. Beskina, A. Abramov, A. G. Gabodulkhakova, A. V. Miller, V. G. Safronova, and M. V. Zamaraeva, "Possible mechanisms of antioxidant activity of glycyrrhizic acid," Biomeditsinskaya Khimiya, vol. 52, no. 1, pp. 60-68, 2006.

[34] N. Saeed, M. R. Khan, and M. Shabbir, "Antioxidant activity, total phenolic and total flavonoid contents of whole plant extracts Torilis leptophylla L," BMC Complementary and Alternative Medicine, vol. 12221 pages, 2012.

[35] M. S. Wani, R. C. Gupta, A. H. Munshi, and S. K. Pradhan, "Phytochemical screening, total phenolics, flavonoid content and antioxidant potential of different parts of Betula utilis D. Don from Kashmir Himalaya," International Journal of Pharmaceutical Sciences and Research, vol. 9, no. 6, pp. 2411-2417, 2018.

[36] M. N. Alam, N. J. Bristi, and M. Rafiquzzaman, "Review on in vivo and in vitro methods evaluation of antioxidant activity," Saudi Pharmaceutical Journal, vol. 21, no. 2, pp. 143-152, 2013.

[37] N. Hoque, M. Z. Imam, S. Akter et al., "Antioxidant and antihyperglycemic activities of methanolic extracts of Glinus oppositifolius leaves," Journal of Applied Pharmaceutical Science, vol. 1, no. 7, pp. 50-53, 2011.

[38] P. Sakong, T. Khampitak, U. Cha et al., "Antioxidant activity and bioactive phytochemical contents of traditional medicinal plants North East Thailand," Journal of Medicinal Plant Research, vol. 5, no. 31, pp. 6822-6831, 2011.

[39] R. A. Khan, M. R. Khan, S. Sahreen, and M. Ahmed, "Evaluation of phenolic contents and antioxidant activity of various solvent extracts of Sonchus asper (L.) Hill," Chemistry Central Journal, vol. 6, no. 12, 2012.

[40] A. M. Pisoschi and G. P. Negulescu, "Methods for total antioxidant activity determination: a review," Biochemistry and Analytical Biochemistry, vol. 1, no. 1, 2011.

[41] R. A. Larson, "The antioxidants of higher plants," Phytochemistry, vol. 27, no. 4, pp. 969-978, 1988.

[42] R. J. Williams, J. P. E. Spencer, and C. Rice-Evans, "Flavonoids: antioxidants or signalling molecules?" Free Radical Biology and Medicine, vol. 36, no. 7, pp. 838-849, 2004.

[43] D. Amic, D. Davidovic-Amic, D. Beslo, and N. Trinajstic, "Structure-radical scavenging activity relationship of flavonoids," Croatica Chemica Acta, vol. 76, no. 1, pp. 55-61, 2003.

[44] M. Oktay, İ. Küfrevioğlu, and I. Kufrevioglu, "Determination of in vitro antioxidant activity of fennel (Foeniculum vulgare) seed extracts," LWT-Food Science and Technology, vol. 36, no. 2, pp. 263-271, 2003.

[45] M. Abbas, F. Saeed, F. M. Anjum et al., "Natural polyphenols: an overview," International Journal of Food Properties, vol. 20, no. 8, pp. 1689-1699, 2017.

[46] P. Karak, "Biological activities of flavonoids: an overview," International Journal of Pharmaceutical Sciences and Research, vol. 10, no. 4, pp. 1567-1574, 2019.

[47] C. K. Kokate, A. P. Purohit, and S. B. Gokhale, Text Book of Pharmacognosy, 13th edition, 2006.

[48] H. Hewageegana, L. Arawwawala, M. Tissera, H. Ariyawansa, and I. Dhammaratana, "A comparison of the physicochemical and phytochemical parameters of glands/hairs of fruits and leaves of Mallotus philippensis (Lam.) Muell. Arg. grown in Sri Lanka," Journal of the National Science Foundation of Sri Lanka, vol. 42, no. 3, pp. 291-295, 2014.

[49] P. K. Mukherjee, Quality Control of Herbal Drugs, New Delhi, India, 2002. 
[50] J. Lincy and G. Mathew, "Pharmacognostical profiling of Geranium ocellatum leaves," International Journal of Medicinal and Aromatic Plants, vol. 1, no. 3, pp. 351-354, 2011.

[51] K. M. Nadkarni, Indian Materia Medica Volume I and II, Popular Prakashan (PVT) Ltd, Mumbai, India, 1st edition, 1976.

[52] N. Z. Sayed and U. Mukundan, Medicinal And Aromatic Plants Of India, Part I, Ukaaz Publications, Hyderabad, India, 2005.

[53] B. N. Devendra, N. Srinivas, and K. S. Solmon, "A comparative pharmacological and phytochemical analysis of in vivo \& in vitro propagated Crotalaria species," Asian Pacific Journal of Tropical Medicine, vol. 5, no. 1, pp. 37-41, 2012.

[54] D. W. Nyamai, W. Arika, P. E. Ogola, E. N. M. Njagi, and M. P. Ngugi, "Medicinally important phytochemicals: an updated research avenue. Research and Reviews," Journal of Pharmacognosy and Phytochemistry, vol. 4, no. 1, pp. 35-49, 2016.

[55] M. Just, M. Recio, R. Giner et al., "Anti-inflammatory activity of unusual lupane saponins from Bupleurum fruticescens," Planta Medica, vol. 64, no. 5, pp. 404-407, 1998.

[56] A. E. A. El-Wahab, D. A. Ghareeb, E. E. M. Sarhan, M. M. Abu-Serie, and M. A. E. I. Demellawy, "In vitro biological assessment of berberis vulgaris and its active constituent, berberine: antioxidants, anti-acetylcholinesterase, antidiabetic and anticancer effects," BMC Complementary and Alternative Medicine, vol. 13218 pages, 2013.

[57] C. Y. Chen, H. Li, Y. N. Yuan, H. Q. Dai, and B. Yang, "Antioxidant activity and components of a traditional Chinese medicine formula consisting of Crataegus pinnatifida and Salvia miltiorrhiza," BMC Complementary and Alternative Medicine, vol. 13, no. 99, 2013.

[58] J. K. Willcox, S. L. Ash, and G. L. Catignani, "Antioxidants and prevention of chronic disease," Critical Reviews in Food Science and Nutrition, vol. 44, no. 4, pp. 275-295, 2004.

[59] V. Matteo and E. Esposito, "Biochemical and therapeutic effects of antioxidants in the treatment of alzheimers disease, Parkinsons disease, and amyotrophic lateral sclerosis," Current Drug Target-CNS \& Neurological Disorders, vol. 2, no. 2, pp. 95-107, 2003. 